\title{
Medicinal Chemistry Strategies for the Development of Kinase Inhibitors
}

\section{Targeting Point Mutations}

Xiaoyun Lu, ${ }^{*} \dot{\dagger}$ Jeff B. Smaill,,+ Ke Ding $*, \dot{\dagger}$

\section{Supporting information}

Table S1 The approved 59 small molecule kinase inhibitors (SMKIs) from 2001 to May 2020.

\begin{tabular}{|c|c|c|c|c|c|}
\hline Name & Structure & Target & Indication & Company & year \\
\hline Capmatinib & Net & NovC with MET exon 14 & Novartis \\
skipping mutation & & \\
\hline Tucatinib & & & & Seattle Genetics & 2020 \\
\hline
\end{tabular}




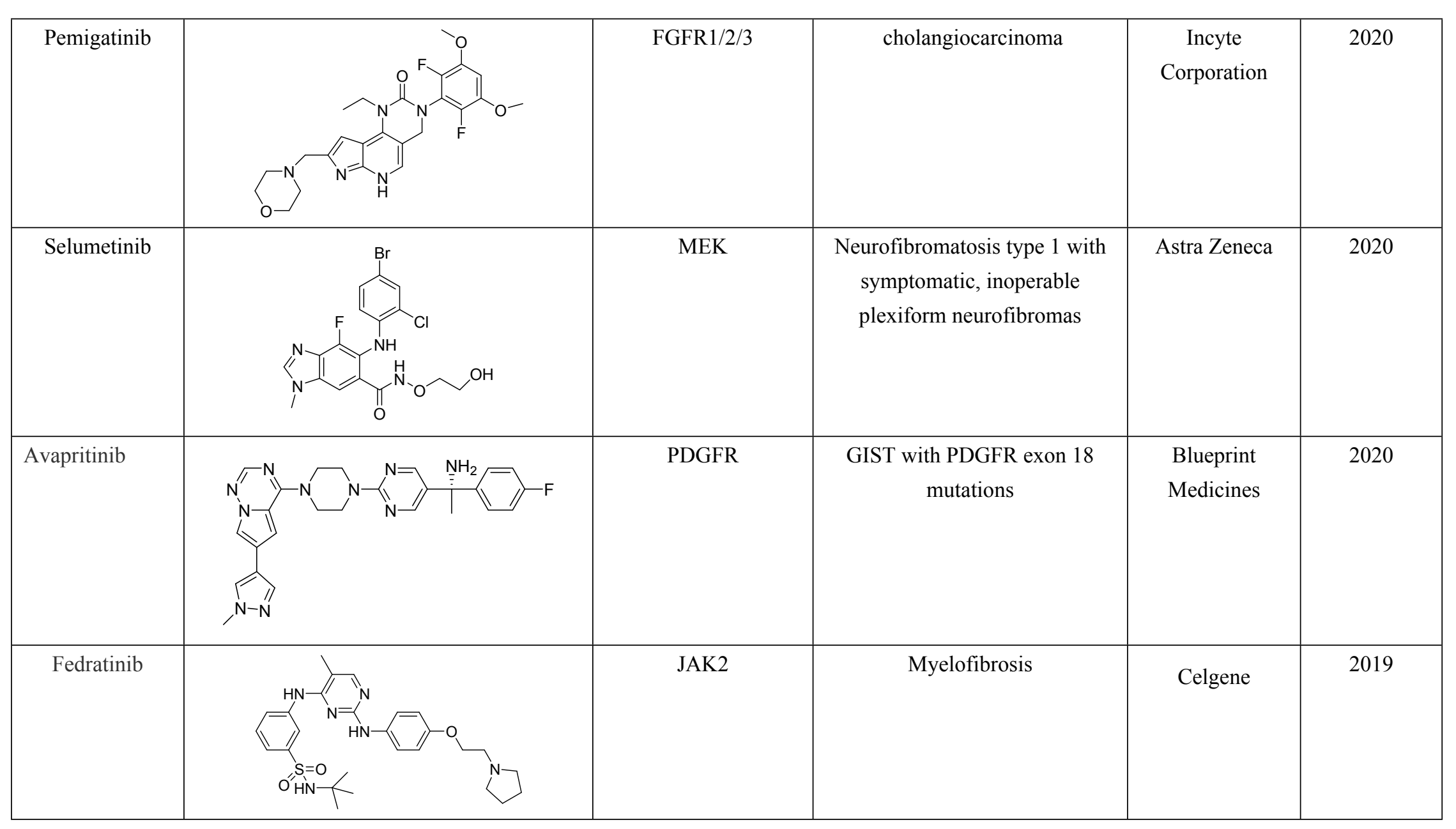




\begin{tabular}{|c|c|c|c|c|c|}
\hline Pexidartinib & . & CSF1R & TGCT & Daiichi Sankyo & 2019 \\
\hline Erdafitinib & & FGFRs & Urothelial cancer & Janssen & 2019 \\
\hline Alpelisib & & PI3K $\alpha$ & Breast cancer & Novartis & 2019 \\
\hline Entrectinib & & TRK & $\begin{array}{l}\text { Solid tumors with NTRK fusion } \\
\text { proteins }\end{array}$ & Roche & 2019 \\
\hline Upadacitinib & & JAK1 & $\begin{array}{c}\text { Moderate/severe rheumatoid } \\
\text { arthritis }\end{array}$ & Abbvie & 2019 \\
\hline
\end{tabular}




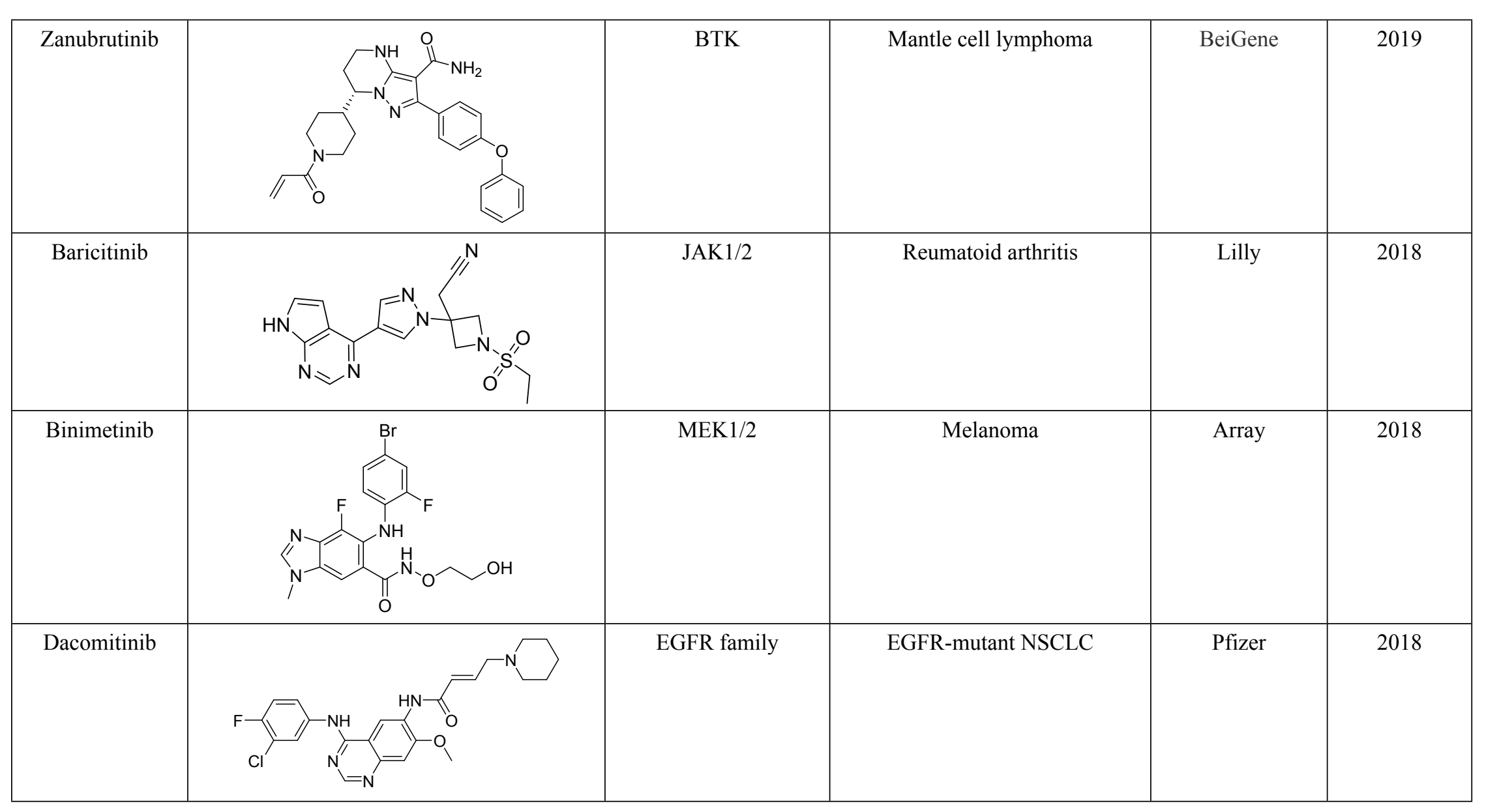




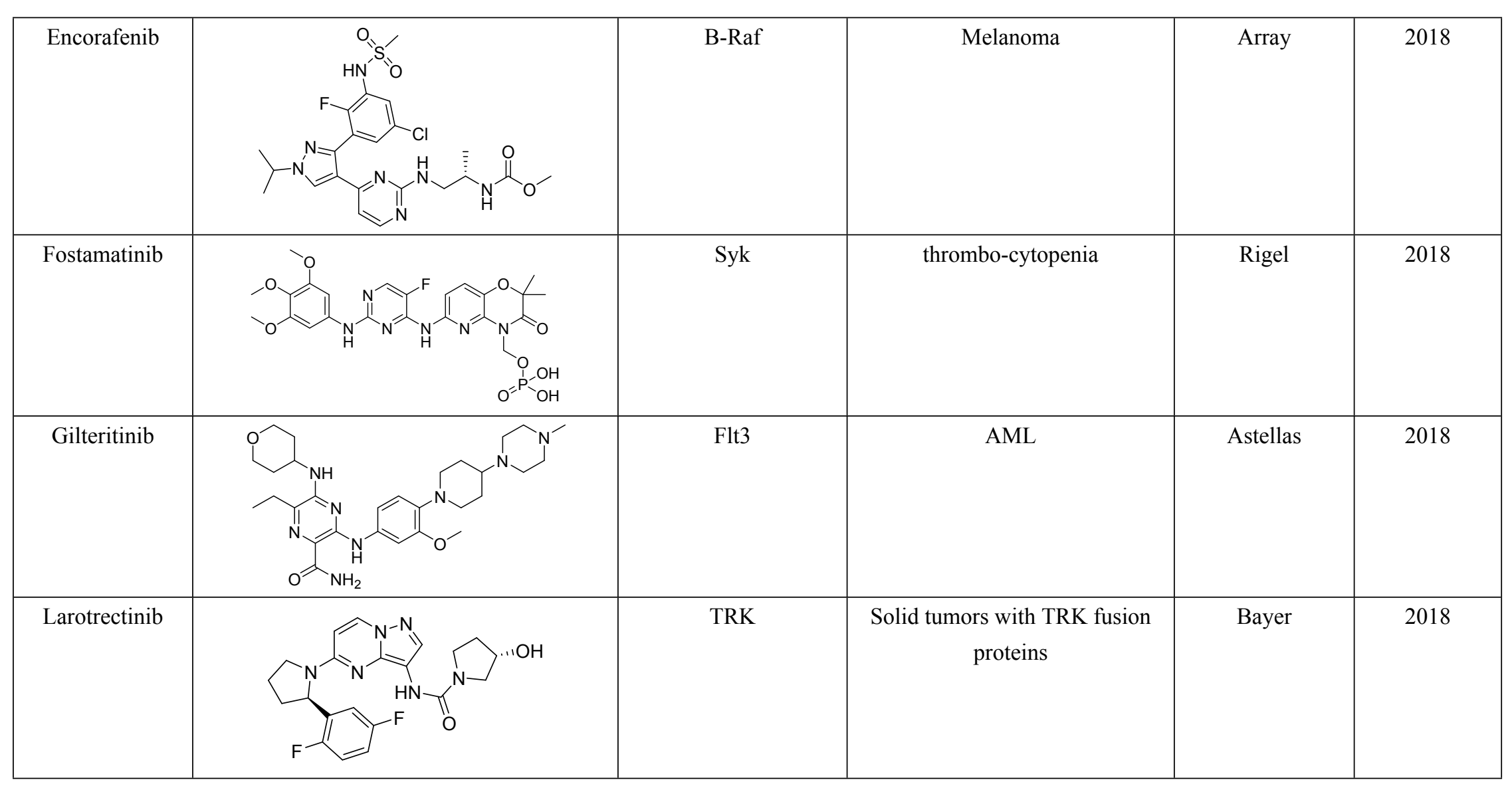




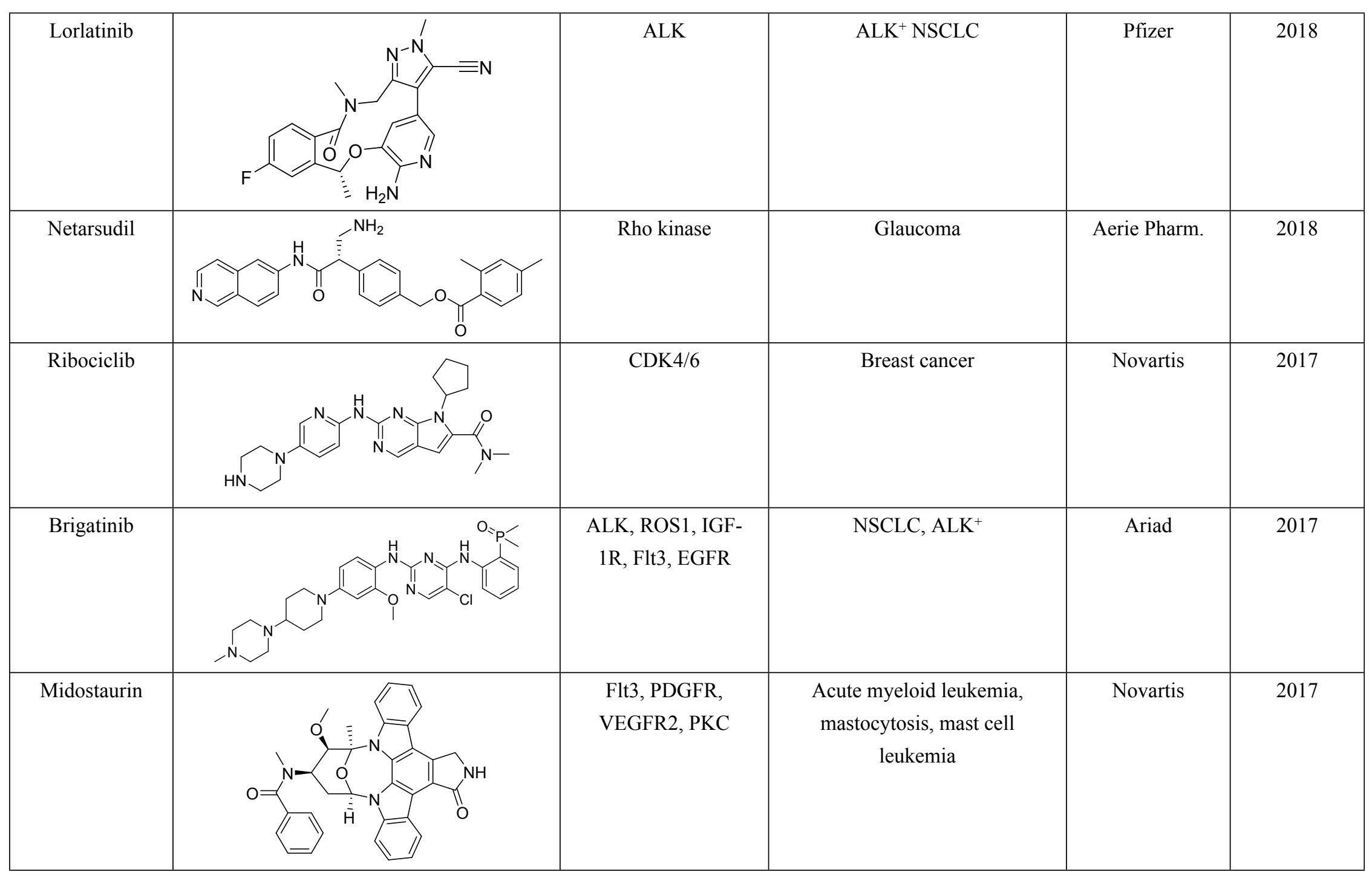




\begin{tabular}{|c|c|c|c|c|c|}
\hline Neratinib & & ErbB2/HER2 & $\mathrm{HER}^{+}{ }^{+}$breast cancer & Puma & 2017 \\
\hline Copanlisib & & PI3K & Relapsed follicular lymphoma & Bayer & 2017 \\
\hline Abemaciclib & & CDK4/6 & Breast $\mathrm{Ca}$ & Lilly & 2017 \\
\hline Acalabrutinib & & BTK & Mantle cell lymphoma & Acerta Pharma & 2017 \\
\hline Palbociclib & $\mathrm{HN}^{-}$ & CDK4/6 & Breast cancer, $\mathrm{ER}^{+}$and $\mathrm{HER} 2^{+}$ & pfizer & 2015 \\
\hline
\end{tabular}




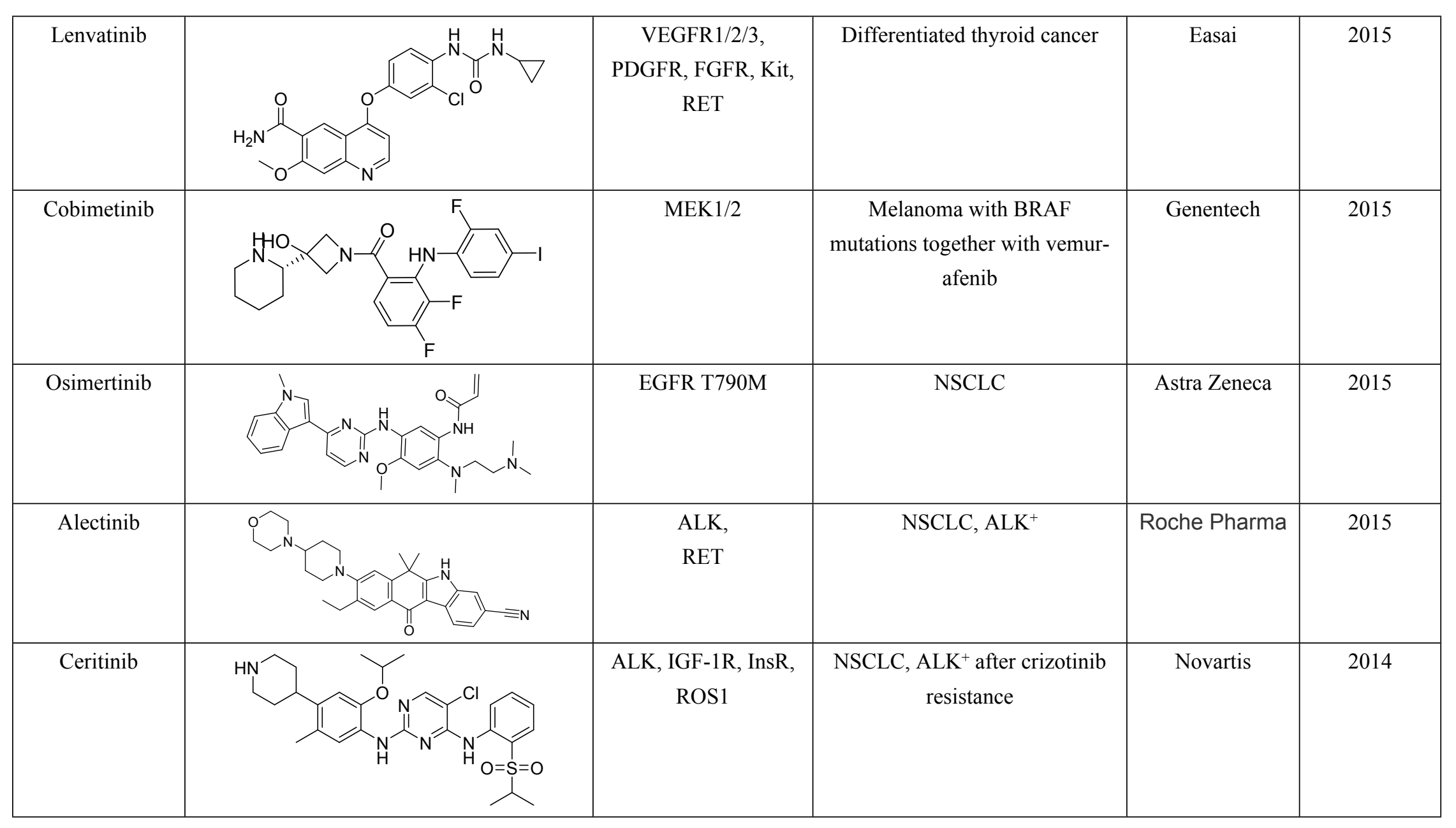




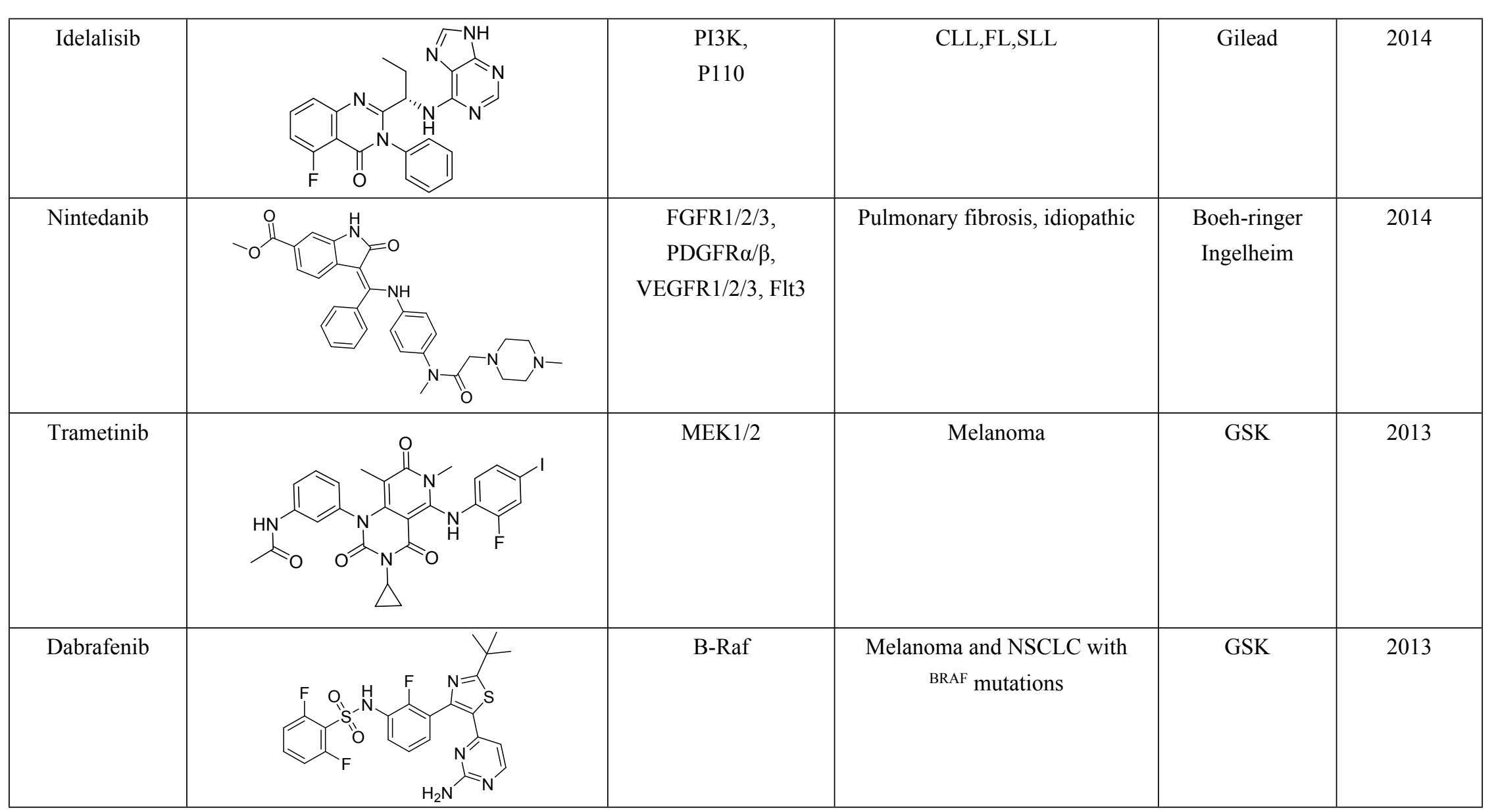




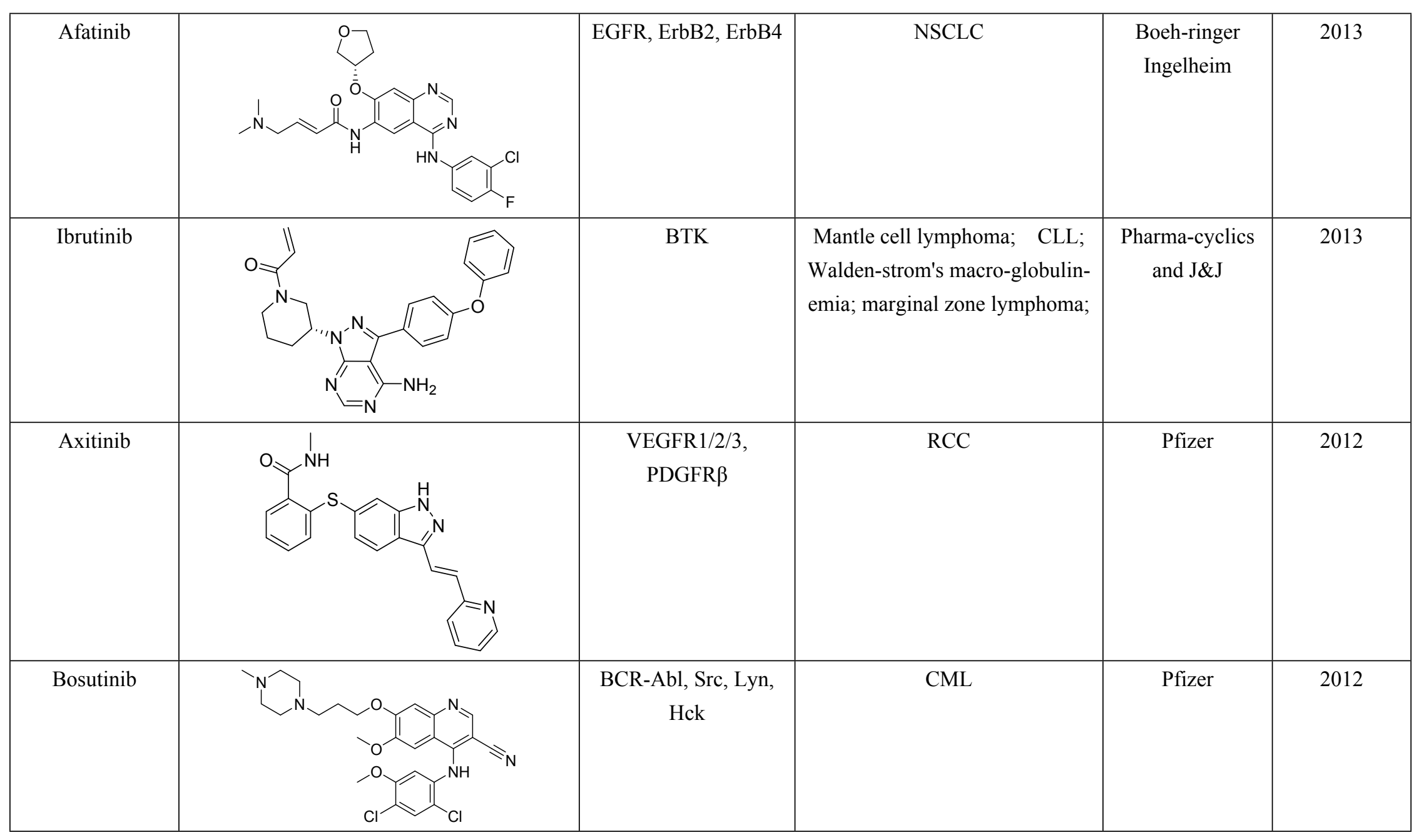




\begin{tabular}{|c|c|c|c|c|c|}
\hline Regorafenib & $\overbrace{F}^{C l}$ & $\begin{array}{c}\text { VEGFR1/2/3, BCR- } \\
\text { Abl, B-Raf, B-Raf } \\
\text { (V600E), Kit, } \\
\text { PDGFR } \alpha / \beta, \text { RET, } \\
\text { FGFR1/2, Tie2, } \\
\text { Eph2A }\end{array}$ & CRC, HCC, GIST & Bayer & 2012 \\
\hline Tofacitinib & & JAK3 & RA, PA, UC & Pfizer & 2012 \\
\hline Cabozantinib & & $\begin{array}{c}\text { RET, MET, } \\
\text { VEGFR1/2/3, Kit, } \\
\text { TrkB, Flt3, Axl, Tie2 }\end{array}$ & $\begin{array}{l}\text { RCC, HCC, medullary thyroid } \\
\text { cancer }\end{array}$ & Excelixis & 2012 \\
\hline Ponatinib & & $\begin{array}{c}\text { BCR-Abl, BCR-Abl } \\
\text { T315I, VEGFR, } \\
\text { PDGFR, FGFR, } \\
\text { EphR, Src family } \\
\text { kinases, Kit, RET, } \\
\text { Tie2, Flt3 }\end{array}$ & CML or ALL, $\mathrm{Ph}+$ & Ariad & 2012 \\
\hline Vandetanib & & $\begin{array}{c}\text { RET, EGFRs, } \\
\text { VEGFRs, Brk, Tie2, } \\
\text { EphRs, and Src } \\
\text { family kinases }\end{array}$ & Thyroid cancer, medullary & AstraZeneca & 2011 \\
\hline
\end{tabular}




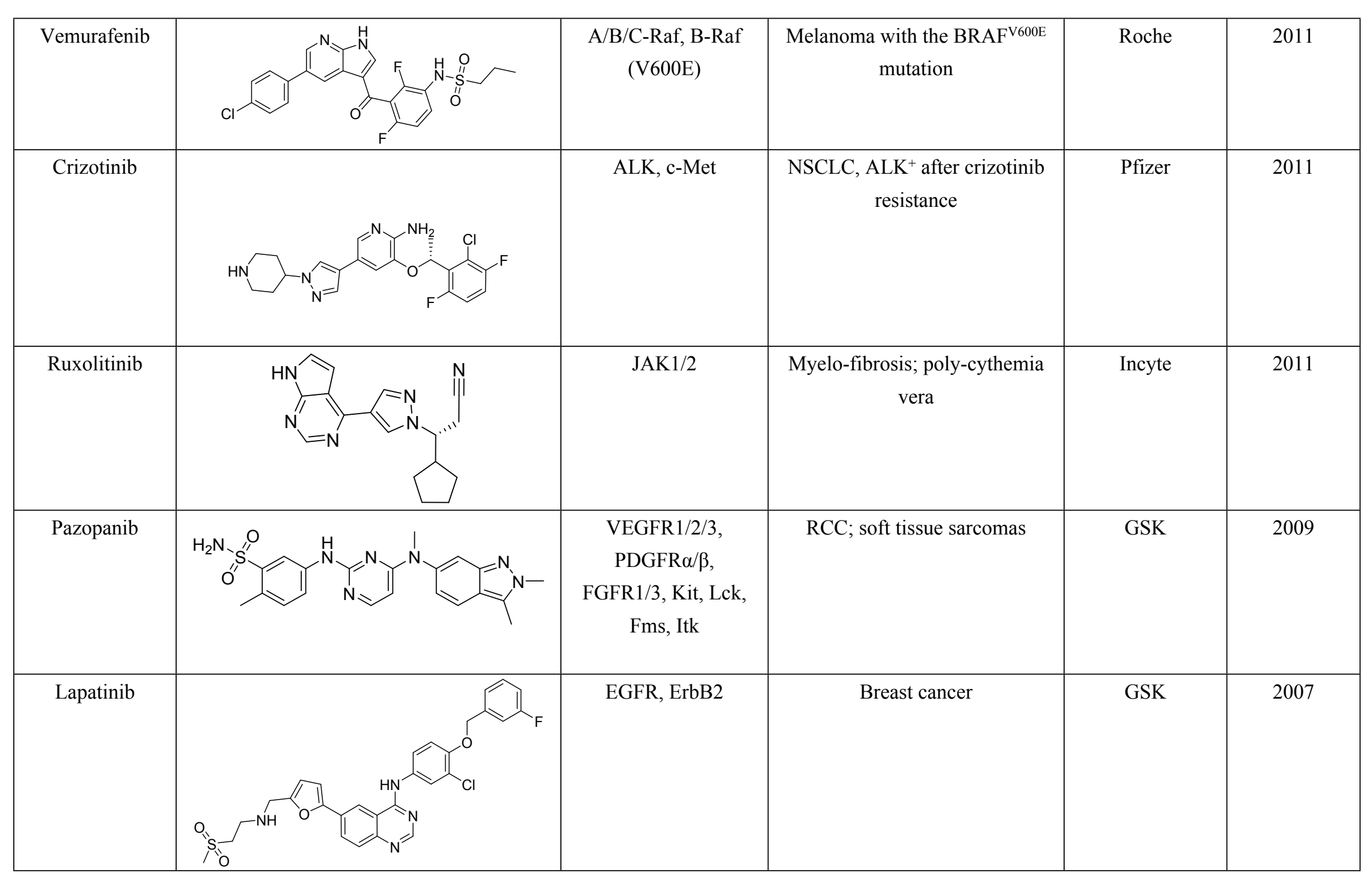




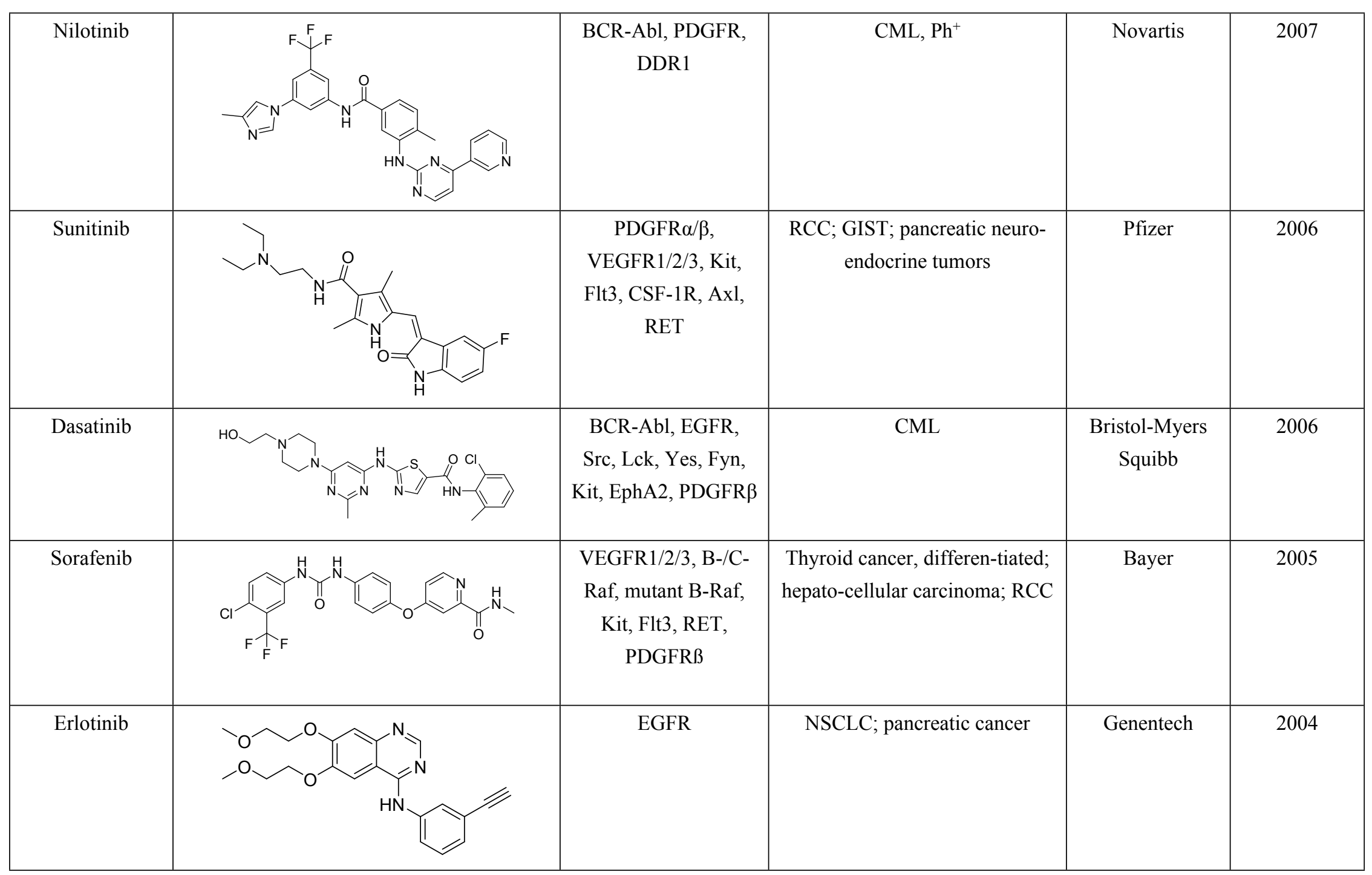




\begin{tabular}{|l|l|l|l|}
\hline Gefitinib & Astra Zeneca \\
\hline Imatinib & COML and ALL, Ph'; aggressive \\
systemic masto-cytosis; CEL; \\
DFSP; HES; GIST
\end{tabular}

ALL, acute lymphoblastic leukemia, CEL, chronic eosinophilic leukemia; CLL, chronic lymphocytic leukemia; CML, chronic myelogenous leukemia; CRC, colorectal cancer; DDR1, Discoidin domain receptor family, member 1; DFSP, dermatofibrosarcoma protuberans; GIST, gastrointestinal stromal tumor; HES, hypereosinophilic syndrome, HGFR, hepatocyte growth factor recepter; MDS/MPD, myelodisplastic/myeloproliferative diseases; MST1R, macrophage-stimulating protein receptor aka RON (Recepteur d'Origine Nantais); NSCLC, non-small cell lung cancer; PNET, progressive neuroendocrine tumors of pancreatic origin; $\mathrm{Ph}+$, Philadelphia chromosome positive; PA, psoriatic arthritis; RA, rheumatoid arthritis; RCC, renal cell carcinoma; UC ulerative colitis. 